\title{
Uji Kesesuaian Aseptic Dispensing Berdasarkan Pedoman Dasar Dispensing Sediaan Steril Departemen Kesehatan RI di ICU dan NICU RSUD Dr. Saiful Anwar Malang
}

\author{
Fradita Nurita Ulfa, Anisyah Achmad", Efta Triastuti \\ Jurusan Farmasi, Fakultas Kedokteran, Universitas Brawijaya, Indonesia
}

INFO ARTIKEL

Sejarah artikel:

Penerimaan naskah:

29 Maret 2017

Penerimaan naskah

revisi: 8 Desember

2017

Disetujui untuk

dipublikasikan: 29

Desember 2017

\section{Kata kunci :}

Aseptic Dispensing,

ICU, NICU,

Pencampuran,

Sediaan Parenteral
A B S T R A K

Aseptic dispensing adalah salah satu metode untuk meminimalisir sediaan farmasi dari bahaya pirogen dan kontaminan. Metode ini meliputi tahap penyiapan, pencampuran, penyimpanan, dan pembuangan. Setiap tahap erat kaitannya dengan ketersediaan sumber daya manusia, peralatan, dan ruang. Sehingga diperlukan teknik yang benar dalam melakukan pencampuran sediaan parenteral. Tujuan dari penelitian ini untuk mengetahui kesesuaian aseptic dispensing di ICU dan NICU RSUD DR. Saiful Anwar Malang berdasarkan Pedoman Dasar Dispensing Sediaan Steril Depkes RI Tahun 2009 dan faktor- faktor yang mendukung kesesuaian tersebut. Penelitian telah mendapatkan ijin etik Fakultas Kedokteran Universitas Brawijaya. Penelitian ini menggunakan metode pengumpulan data secara observasional deskriptif dengan lembar checklist dan angket yang kemudian dianalisis secara kuantitatif. Analisis ketersediaan peralatan dan ruang dilakukan secara kualitatif. Diperoleh hasil penelitian bahwa dari 110 pencampuran, kesesuaian tahap penyiapan 87,77\%, pencampuran 49,09\%, penyimpanan $80 \%$, dan pembuangan $98,18 \%$. Data pendukung faktor yang mempengaruhi aseptic dispensing adalah sumber daya manusia. Hasil angket tingkat pengetahuan tentang aseptic dispensing sebanyak $60 \%$ responden sangat baik, 33\% baik, $7 \%$ cukup. Ketersediaan peralatan dan ruang belum sesuai dengan pedoman. Kesimpulan penelitian adalah aseptic dispensing dalam pencampuran sediaan steril parenteral di ICU dan NICU RSUD Dr. Saiful Anwar Malang belum sesuai dengan pedoman pada tahap pencampuran $(<50 \%)$.

\section{The Suitability Evaluation of Aseptic Dispensing Regarding to Indonesian Department of Health Basic Guidance of Sterile Preparation Dispensing in ICU and NICU Units of RSUD Dr. Saiful Anwar Malang}

\section{Keywords:}

Aseptic Dispensing,

Preparations,

Parenteral

\section{A B S T R A C T}

The aseptic dispensing is a method to minimize the pyrogens and contaminants of pharmaceutical preparations. This method consists of several stages, which are preparation stage, dispensing stage, storage stage, and disposal stage. Each procedures closely related with the availability of human resources, equipment, and rooms. Hence this technique is required to perform parenteral preparations dispensing. The purpose of this study was to determine the suitability level of aseptic dispensing technique in ICU and NICU RSUD Dr. Saiful Anwar Malang regarding to Indonesian Basic Guidance of Sterile Preparation Dispensing (2009) and the factors affecting. The method of the data collection was descriptive observational which then analysed by quantitative description using the checklist sheet, the questionnaire, and availability of equipment. As the secondary outcome, the presentation of the aseptic rooms was analysed qualitatively. The result showed that out of 110 dispensing processes $88.77 \%$ were suitable in the preparation, $49.09 \%$ were suitable in the mixing process, otherwise $80 \%$ were suitable in the storage process, and $98.18 \%$ from disposal process were suitable. Supporting data affecting the aseptic dispensing is human resources from the questionnaire of the aseptic dispensing knowledge. The results of this questionnaire revealed $60 \%$ outstanding level of knowledge, $33 \%$ were good, and $7 \%$ were decent. The availability of equipment and rooms were not complete. This study concluded that several of the aseptic dispensing process in ICU and NICU RSUD Dr. Saiful Anwar Malang were improper regarding the guidance in dispensing stage $(<50 \%)$.

\footnotetext{
* Corresponding author: Anisyah Achmad, Jurusan Farmasi Fakultas Kedokteran Universitas Brawijaya, Jalan Veteran Malang 65145, Telp: +62-341-551611, Fax: +62-341-565420. E-mail: r3600mc@yahoo.com
} 


\section{Pendahuluan}

Pelayanan kefarmasian menurut PP No.51 tahun 2009 adalah pelayanan langsung dan bertanggung jawab kepada pasien berkaitan dengan sediaan farmasi agar mencapai hasil yang pasti untuk meningkatkan mutu kehidupan pasien. Apoteker bertanggung jawab dalam keberlangsungan pemberian pengobatan yang diatur dengan SPO (Standar Prosedur Operasional).

IFRS (Instalasi Farmasi Rumah Sakit) bertanggung jawab terhadap sediaan obat dari pengadaan hingga distribusi ke pasien,ketepatan dosis, rute pemberian,dan penjaminan mutu obat, terutama sediaanparenteral. ${ }^{1}$ Pencampuran sediaan parenteral merupakan pencampuran obat yang menghasilkan produk baru dengan proses pelarutan atau penambahan bahan lain yang dilakukan oleh apoteker secara aseptis. $^{2}$

Dispensing sediaan steril merupakan layanan kefarmasian yang dilaksanakan di rumah sakit. Permenkes No. 58 Tahun 2014 tentang standar pelayanan kefarmasian di rumah sakit, pelayanan ini seharusnya dilaksanakan di IFRS. Hal ini bertujuan untuk mencegah terjadinya infeksi nosokomial, kontaminasi sediaan, paparan terhadap petugas dan lingkungan, mencegah risiko kesalahan terkait penggunaan sediaan obat, dan untuk menjamin kualitas mutu sediaan. Meskipun demikian, di Inggris pelayanan CIVAS (Centralized Intravenous Admixture Service) atau pelayanan pencampuran sediaan terpusat belum sepenuhnya dilaksanakan dan pada umumnya masih dilaksanakan oleh perawat. $^{3}$

Syarat yang harus dipenuhi dalam pencampuran sediaan parenteral secara aseptis adalah ruang bersih, kabinet LAF (Laminar Air Flow), dan personel yang berkompeten memenuhi syarat sebagai petugas dispensing. SDM harus mendapatkan pelatihan secara berkala untuk meningkatkan pengetahuan dan menjamin mutu pelayanan. Pelatihan dapat dilaksanakan oleh IFRS atau pelatihanpelatihan dari instansi terkait. IFRS juga harus membuat tim jaminan mutu produk dan pencampuran sediaan parenteral agar mutu terjamin dan meminimalisir terjadinya kesalahan. ${ }^{1}$

Pasien rawat inap banyak diresepkan sediaan parenteral karena lebih cocok untuk keadaan darurat, onset cepat, dan menjadi pilihan terapi pasien yang tidak kooperatif dengan sediaan obat oral. Kendala pencampuran sediaan steril parenteral seperti risiko terjadinya ketidakstabilan, dan adanya kontaminan yang mengakibatkan timbulnya risiko gangguan pada pembuluh darah seperti emboli dan phlebitis. ${ }^{4}$

Untuk menghindari adanya zat berbahaya pada sediaan parenteral diperlukan teknik aseptic dispensing agar tidak menimbulkan efek negatif bagi pasien maupun tenaga kesehatan yang bertugas. Faktor-faktor pendukung dalam prosedur aseptis diantaranya adalah sumber daya manusia (SDM), fasilitas ruangan, dan peralatan. ${ }^{5}$ SPO diperlukan untuk mengatur tentang aseptic dispensing.

Pemberian obat secara parenteral pada ruang perawatan kritis atau Intensive Care Unit (ICU) dan di
Neonatal Intensive Care Unit (NICU) memerlukan perhatian khusus, karena pasien dengan keadaan kritis memiliki pertahanan tubuh lebih kecil terhadap efek samping pemberian obat dibandingkan dengan pasien lain. ${ }^{6}$ Risiko kesalahan dalam pencampuran meningkat karena informasi yang tidak cukup mengenai kompatibilitas obat dan pencampurannya secara steril atau aseptis. ${ }^{7}$ Penelitian ini dilakukan untuk mengetahui kesesuaian pelaksanaan aseptic dispensing pada pencampuran sediaan parenteral di ICU dan NICU Rumah Sakit Umum Daerah Dr. Saiful Anwar Malang berdasarkan Buku Pedoman Dasar Dispensing Sediaan Steril Departemen Kesehatan Republik Indonesia 2009.

\section{Metode}

Penelitian dilakukan secara observasional dengan analisa deskriptif kuantitatif dan pendekatan cross sectional. Penelitian dilaksanakan di RSUD Dr. Saiful Anwar Malang bulan April-Mei 2015. Penelitian ini sudah mendapatkan izin etik Fakultas Kedokteran Universitas Brawijaya Malang dengan No 160/EC/KEPK-S1-FARM /02/ 2015. Sampel inklusi adalah pencampuran sediaan parenteral yang dilaksanakan di ICU dan NICU bulan April-Mei 2015 pada pukul 7.00-9.00 dan 15.00-17.00 WIB dan dapat diamati oleh peneliti secara langsung, sedangkan kriteria eksklusi adalah pencampuran yang dilaksanakan di luar jadwal pengambilan sampel. Besar sampel yang ditetapkan adalah 110 sampel.

Teknik pengambilan sampel non random sampling dengan menggunakan instrumen Buku Pedoman Dasar Dispensing Sediaan Steril Depkes RI Tahun 2009, lembar pengumpul data prosedur aseptic dispensing dan lembar borang khusus keadaan tidak terdapat LAF-BSC serta angket yang diberikan ke tenaga pendispensing sebagai data pendukung tingkat pengetahuan SDM yang mendukung pelaksanaan aseptic dispensing. Lembar pengumpul data terbagi atas 4 tahap (penyiapan, pencampuran, penyimpanan, dan pembuangan). Angket terdiri atas 8 pertanyaan pengetahuan SDM tentang aseptic dispensing. Data dianalisis secara deskriptif kuantitatif dengan skala Guttman, sesuai apabila persentase kesesuaian $\geq 50 \%$ dan tidak sesuai apabila $<50 \%$.Data sekunder berupa angket dianalisis secara deskriptif kuantitatif, persentase yang diperoleh diinterpretasikan menggunakan kategori oleh Arikunto, 2006 yakni baik sekali $(80 \%-100 \%)$, baik $(66 \%$ $79 \%)$, cukup (56\%-65\%), kurang $(40 \%-55 \%)$, dan gagal $(<40 \%)$ dengan persentase maksimal $100 \% .^{2}$

\section{Hasil}

Hasil penelitian diperoleh sampel 110 tindakan pencampuran (98 di ICU dan 12 di NICU), dan 15 responden mengisi angket pengetahuan aseptic dispensing. Persentase kesesuaian aseptic dispensing menurut Pedoman Dasar Dispensing Sediaan Steril Depkes RI Tahun 2009 yaitu tertinggi pada tahap pembuangan sebanyak 108 pencampuran $(98,18 \%)$ dan kesesuaian terendah pada tahap 
pencampuran yakni 54 pencampuran (49,09\%) (Gambar 1; Gambar 2).

\section{Persentase kesesuaian aseptic dispensing menurut Pedoman Dasar Dispensing Sediaan Steril Depkes RI Tahun 2009 di ICU dan NICU RSUD Dr. Saiful Anwar Malang}

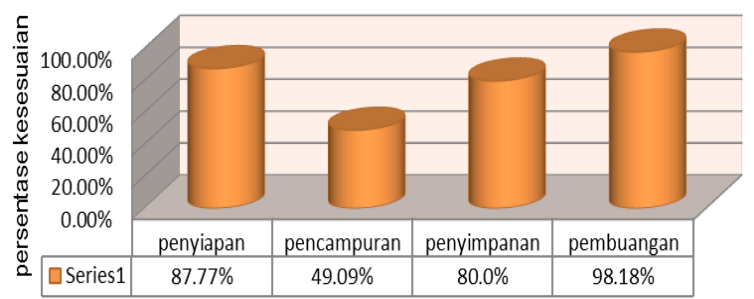

Gambar 1. Distribusi Frekuensi Persentase Kesesuaian Aseptic Dispensing di ICU dan NICU RSUD Dr. Saiful Anwar Malang

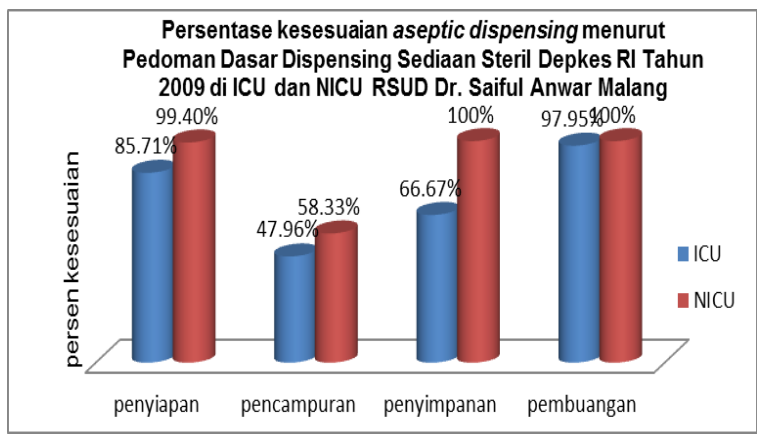

Gambar 2. Distribusi Frekuensi Persentase Aseptic Dispensing di ICU dan NICU RSUD Dr. Saiful Anwar Malang

Pada tahap penyiapan (Gambar 3), kesesuaian cuci tangan sesuai SPO sebesar 100\% dan menggunakan APD sebesar 74,54\%. Pada tahap menggunakan APD (Tabel 1) diperoleh kesesuaian $100 \%$ pada tahap melepas dan menyimpan pakaian, sedangkan terendah pada membuka pintu penyangga sebesar 11\% (10 tindakan pencampuran).

Tahap Penyiapan

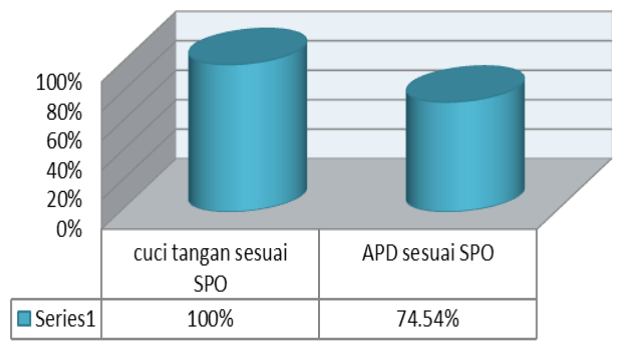

Gambar 3. Distribusi Frekuensi Persentase Kesesuaian Aseptic Dispensing Tahap Penyiapan

Pada tahap pencampuran kesesuaian terendah pada tahap memasukkan bahan melalui passbox sebanyak $0 \%$ dan kesesuaian tertinggi pada tahap pencampuran $78,18 \%$.

Pada poin pencampuran kesesuaian tertinggi adalah menyeka alat dan bahan dengan alkohol sebelum dan setelah digunakan, mencampurkan obat secara aseptis, dan membuang kasa ke kontainer sebesar $100 \%$. Kesesuaian terendah yaitu membersihkan meja kerja dengan detergen sebesar 0\% (Tabel 2). Kesesuaian tertinggi poin menanggal APD sesuai dengan SPO (Tabel 3) adalah cuci tangan sebesar $100 \%$ dan kesesuaian terendah yaitu menanggalkan sarung tangan dalam sebesar 9,09\% (10 pencampuran).

Tabel 1. Kesesuaian Petugas Menggunakan APD sesuai dengan SPO Pedoman Dasar Dispensing Sediaan Steril Depkes RI 2009

\begin{tabular}{|c|c|c|c|}
\hline No & Proses & Jumlah & $\begin{array}{c}\text { Persentase } \\
(\%)\end{array}$ \\
\hline 1. & $\begin{array}{l}\text { Pakaian steril disimpan \& ditangani } \\
\text { sedemikian rupa setelah dicuci dan } \\
\text { disterilkan. }\end{array}$ & 110 & 100 \\
\hline 2. & $\begin{array}{l}\text { Arloji, perhiasan dilepaskan dan } \\
\text { disimpan ke lemari penyimpanan. }\end{array}$ & 110 & 100 \\
\hline 3. & $\begin{array}{l}\text { Pakaian dan sepatu dilepas, disimpan } \\
\text { di tempat yang telah disediakan. }\end{array}$ & 110 & 100 \\
\hline 4. & $\begin{array}{l}\text { Penutup kepala menutup rambut } \\
\text { diselipkan ke leher baju terusan, } \\
\text { masker, penutup kaki sampai ujung } \\
\text { kaki, celana/baju terusan diselipkan ke } \\
\text { penutup kaki \& menggunakan } \\
\text { kacamata pelindung. }\end{array}$ & 73 & 66,36 \\
\hline 5. & $\begin{array}{l}\text { Sarung tangan dibasahi dengan } \\
\text { alkohol } 70 \% \text { atau larutan desinfektan } \\
\text { lainnya. }\end{array}$ & 53 & 48,18 \\
\hline 6. & $\begin{array}{l}\text { Membuka pintu untuk memasuki } \\
\text { ruang penyangga dan ruang steril } \\
\text { hendaknya dengan siku tangan }\end{array}$ & 11 & 10 \\
\hline 7. & $\begin{array}{l}\text { Setelah bekerja melepaskan APD dan } \\
\text { diletakkan pada wadah yang } \\
\text { ditentukan, mengganti pakaian } \\
\text { sebelum keluar dari ruang steril. }\end{array}$ & 99 & 90 \\
\hline
\end{tabular}

Tabel 2. Kesesuaian Prosedur Pencampuran Secara Aseptis (Borang Khusus Tidak Terdapat LAF-BSC)

\begin{tabular}{|c|c|c|c|}
\hline No & Prosedur & Jumlah & $\begin{array}{l}\text { Persentase } \\
(\%)\end{array}$ \\
\hline 1 & Memakai alat pelindung diri. & 102 & 92,73 \\
\hline 2 & $\begin{array}{l}\text { Membersihkan meja kerja dengan } \\
\text { alkohol } 70 \% \text { dengan kain lap tidak } \\
\text { berserat secara searah. }\end{array}$ & 91 & 82,73 \\
\hline 3 & $\begin{array}{l}\text { Menutup permukaan meja kerja } \\
\text { dengan alas kemoterapi siapkan } \\
\text { seluruh peralatan. }\end{array}$ & 13 & 11,82 \\
\hline 4 & $\begin{array}{l}\text { Seka seluruh alat kesehatan dan wadah } \\
\text { obat sebelum digunakan dengan } \\
\text { alkohol } 70 \%\end{array}$ & 110 & 100 \\
\hline 5 & $\begin{array}{lll}\text { Dilakukan } & \text { pencampuran } & \text { secara } \\
\text { aseptis. }\end{array}$ & 110 & 100 \\
\hline 6 & $\begin{array}{l}\text { Seka seluruh alat kesehatan dan wadah } \\
\text { obat yang sudah digunakan dengan } \\
\text { alkohol } 70 \% \text {. }\end{array}$ & 107 & 92,27 \\
\hline 7 & 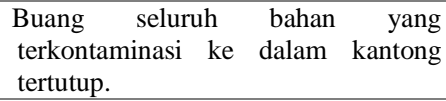 & 110 & 100 \\
\hline 8 & $\begin{array}{l}\text { Membersihkan area kerja dengan } \\
\text { mencuci dengan detergen dan bilas } \\
\text { dengan akuades, diulangi sebanyak } 3 \\
\text { kali, terakhir dibilas dengan akuades }\end{array}$ & 0 & 0 \\
\hline 9 & $\begin{array}{l}\text { Buang seluruh kasa ke dalam kantong } \\
\text { tertutup }\end{array}$ & 110 & 100 \\
\hline 10 & Tanggalkan alat pelindung diri & 105 & 95,45 \\
\hline
\end{tabular}
pencampuran yang disimpan, sebanyak 12 pencampuran (60\%) disimpan sesuai dengan prosedur pada pedoman (Gambar 5). 
Tabel 3. Kesesuaian Prosedur Pelepasan APD sesuai SPO

\begin{tabular}{llccc}
\hline No & \multicolumn{1}{c}{ Prosedur } & Jumlah & $\begin{array}{c}\text { Persentase } \\
(\%)\end{array}$ \\
\hline 1 & $\begin{array}{l}\text { Menanggalkan sarung tangan luar } \\
\text { dengan menempatkan jari-jari sarung } \\
\text { tangan di luar manset. Angkat sarung } \\
\text { tangan luar dengan menarik ke arah } \\
\text { telapak tangan. Diulangi prosedur di } \\
\text { tangan sebaliknya. }\end{array}$ & 91 & 82,73 \\
\hline 2 & $\begin{array}{l}\text { Menanggalkan baju pelindung dengan } \\
\text { membuka ikatan baju pelindung, tarik } \\
\text { keluar dari bahu dan lipat sehingga } \\
\text { bagan luar terletak di dalam, disimpan } \\
\text { di kantong tertutup. }\end{array}$ & 93 & 84,55 \\
\hline 3 & $\begin{array}{l}\text { Menanggalkan tutup kepala dan buang } \\
\text { di kantong tertutup. }\end{array}$ & 58 & 52,73 \\
\hline 4 & $\begin{array}{l}\text { Menanggalkan sarung tangan dalam, } \\
\text { bagian luar tidak boleh menyentuh } \\
\text { kulit dan buang di kantong tertutup. }\end{array}$ & 10 & 9,09 \\
\hline 5 & $\begin{array}{l}\text { Kantong berisi bekas APD dibuang ke } \\
\text { kontainer buangan sisa. }\end{array}$ & 105 & 95,45 \\
\hline 6 & $\begin{array}{l}\text { Cuci tangan sesuai dengan prosedur di } \\
\text { awal }\end{array}$ & 110 & 100 \\
\hline
\end{tabular}

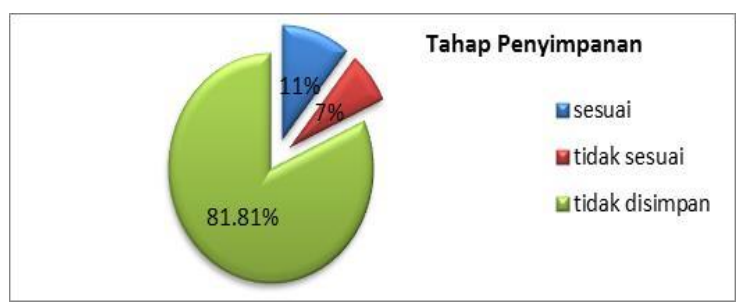

Gambar 5. Distribusi Frekuensi Persentase Kesesuaian Aseptic Dispensing Tahap Penyimpanan.

Pada tahap pembuangan hampir seluruh tahap diperoleh kesesuaian $100 \%$ kecuali tahap menggunakan APD sebesar 87,27\% (96 tindakan pencampuran) (Tabel 4).

Tabel 4. Kesesuaian Prosedur Pembuangan sesuai SPO

\begin{tabular}{clcc}
\hline No & \multicolumn{1}{c}{ Prosedur } & Jumlah & $\begin{array}{c}\text { Persentase } \\
(\%)\end{array}$ \\
\hline 1 & Menggunakan APD. & 96 & 87,27 \\
\hline 2 & $\begin{array}{l}\text { Tempatkan limbah pada kontainer } \\
\text { buangan tertutup (limbah tajam seperti } \\
\text { syringe, vial, ampul diletakkan di } \\
\text { kontainer tidak tembus benda tajam). }\end{array}$ & 110 & 100 \\
\hline 3 & $\begin{array}{l}\text { Diberi label peringatan pada luar } \\
\text { kantong }\end{array}$ & 110 & 100 \\
\hline 4 & $\begin{array}{l}\text { Membawa limbah ke pembuangan } \\
\text { dengan troli tertutup }\end{array}$ & 110 & 100 \\
\hline 5 & Cuci tangan & 110 & 100 \\
\hline
\end{tabular}

Dari 15 angket tingkat pengetahuan yang telah diisi, sebanyak 9 responden $(60 \%)$ memiliki tingkat pengetahuan sangat baik, 5 responden (33\%) baik, dan 1 responden (7\%) cukup (Gambar 6). Jawaban angket nilai terendah soal nomor 3 yaitu keikutsertaan dalam pelatihan aseptic dispensing dan jawaban tertinggi pada soal nomor 6 tentang prosedur cuci tangan sesuai dengan SPO sebelum dan sesudah melakukan pencampuran sediaan parenteral (Tabel 5).

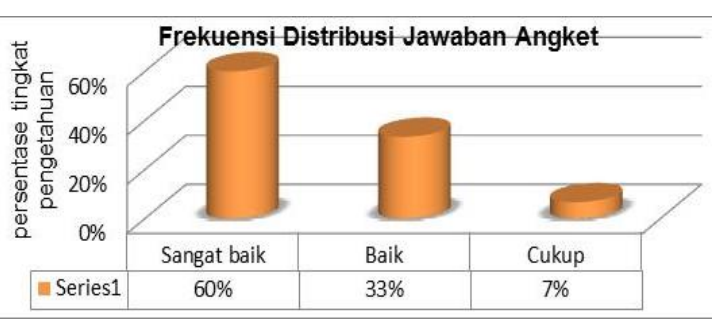

Gambar 6. Distribusi Frekuensi Jawaban Angket Tingkat Pengetahuan tentang Aseptic Dispensing

Tabel 5. Hasil Angket Tingkat Pengetahuan tentang Aseptic Dispensing.

\begin{tabular}{|c|c|c|c|}
\hline No & Pertanyaan & $\begin{array}{l}\text { Jumlah } \\
\text { Nilai }\end{array}$ & $\begin{array}{c}\text { Persentase } \\
(\%)\end{array}$ \\
\hline 1 & $\begin{array}{l}\text { Apakah yang dimaksud aseptic } \\
\text { dispensing atau teknik aseptis? }\end{array}$ & 14 & 93,3 \\
\hline 2 & $\begin{array}{l}\text { Apakah aseptic dispensing perlu dan } \\
\text { wajib dilakukan setiap melakukan } \\
\text { pencampuran sediaan parenteral? }\end{array}$ & 14 & 93,3 \\
\hline 3 & $\begin{array}{l}\text { Apakah sudah pernah mengikuti } \\
\text { pelatihan tentang aseptic } \\
\text { pada dispensing } \\
\text { parenteral? }\end{array}$ & 8 & 53,3 \\
\hline 4 & $\begin{array}{l}\text { Apakah gemar membaca/mencari } \\
\text { referensi tentang aseptic dispensing } \\
\text { pada pencampuran sediaan } \\
\text { parenteral? }\end{array}$ & 11 & 73,3 \\
\hline 5 & $\begin{array}{l}\text { Apakah sudah menerapkan aseptic } \\
\text { dispensing pada saat melakukan } \\
\text { pencampuran sediaan parenteral? }\end{array}$ & 12 & 80 \\
\hline 6 & $\begin{array}{l}\text { Apakah sudah melaksanakan prosedur } \\
\text { cuci tangan sesuai SPO? }\end{array}$ & 15 & 100 \\
\hline 7 & $\begin{array}{l}\text { Apakah sudah menggunakan APD } \\
\text { sesuai dengan SPO? }\end{array}$ & 12 & 80 \\
\hline 8 & $\begin{array}{l}\text { Apakah merasa tidak ada kendala } \\
\text { dalam menerapkan aseptic dispensing } \\
\text { dalam pencampuran sediaan } \\
\text { parenteral? }\end{array}$ & 12 & 80 \\
\hline
\end{tabular}

\section{Diskusi}

Pada Pada hasil penelitian diperoleh sebanyak 110 sampel tindakan pencampuran sediaan parenteral. Kesesuaian tertinggi pencampuran di tahap pembuangan sebesar 98,18\% didukung fasilitas pembuangan yang memadahi di ICU dan NICU RSUD Dr. Saiful Anwar Malang. Kesesuaian terendah pada tahap pencampuran sebesar 49,09\% karena terkendala oleh tidak adanya fasilitas passbox dan LAF-BSC di ruangan. Tahap penyiapan $87,77 \%$ dan tahap penyimpanan $80 \%$ sudah sesuai karena fasilitas dan kompetensi SDM sudah bagus. Persentase kesesuaian lebih tinggi di NICU daripada di ICU karena di NICU terdapat ruang pencampuran obat terpusat yang sudah dikondisikan menyerupai LAF-BSC dan pencampuran dilakukan oleh tenaga kesehatan khusus.

Pada tahap penyiapan diperoleh hasil kesesuaian melakukan cuci tangan sesuai dengan SPO sebanyak 100\% dan menggunakan APD (Alat Pelindung Diri) sesuai dengan SPO sebanyak $74,54 \%$. Fungsi cuci tangan adalah upaya untuk mencegah infeksi nosokomial. Kesesuaian prosedur cuci tangan didukung dengan fasilitas wastafel dan hand $r u b$. Hand rub basis alkohol lebih efektif untuk daripada cuci tangan manual, lebih cepat, rendah risiko iritasi, dan 
meningkatkan kepatuhan dalam hand hygiene. Pedoman cuci tangan di RSSA dibuat oleh Komite PPI (Pengendalian dan Pencegahan Infeksi) sudah tertera di setiap sudut strategis. ${ }^{8}$

Pada tahap menggunakan APD sesuai dengan SPO terdapat kesesuaian tertinggi pada nomor 1,2,3 sebanyak 110 pencampuran $(100 \%)$ dan terendah pada nomor 6 sebanyak 11 pencampuran (10\%). Kesesuaian didukung dengan fasilitas ruang ganti dan istirahat yang memadahi. Perilaku disiplin menggunakan APD dipengaruhi oleh pengawasan dari $\mathrm{K} 3$, faktor pendorong yaitu dimana perilaku dipengaruhi oleh senior atau orang yang berpengalaman sebagai role model dalam mematuhi SPO dan dapat ditiru serta teori Health Belief Model dimana perilaku kesehatan ditentukan atas keyakinan diri apabila tidak disiplin akan muncul bahaya. ${ }^{9}$ Faktor yang memicu ketidakpatuhan menggunakan APD adalah adanya rasa malas dan ketidakcukupan sarana yang tersedia. APD yang sering digunakan adalah masker dan sarung tangan.

Tahap pencampuran terdiri atas tahap memasukkan bahan melalui passbox, tahap pencampuran, dan melepas APD sesuai dengan SPO. Kesesuaian tahap memasukkan bahan melalui passbox sebanyak 0\% karena di ICU dan NICU tidak tersedia passbox. Kesesuaian tahap pencampuran $78,18 \%$ dan tahap melepas APD sesuai dengan SPO 69,09\%. Di ICU dan NICU RSUD Dr. Saiful Anwar Malang tidak memiliki LAF-BSC maka penilaian pada tahap pencampuran menggunakan borang khusus sesuai standar Depkes RI. Dijelaskan pada Tabel 2 bahwa kesesuaian tertinggi pada poin melakukan desinfeksi pada alat dan bahan sebelum dan setelah digunakan dan tahap pencampuran secara aseptis sebesar $100 \%$.Hal ini dilakukan sebagai upaya mencegah timbulnya risiko berkembangnya agen infeksius dan pentingnya keselamatan kerja dalam kewaspadaan universal di ICU dan NICU, ${ }^{10}$ yakni melindungi pasien dan petugas agar tidak terpapar cemaran. Dalam praktek pencampuran di ICU dan NICU tidak menggunakan alas kemoterapi karena obat yang dicampurkan adalah non sitostatika. Namun di NICU tetap diberi alas kemoterapi. Pembersihan dengan detergen diganti dengan pembersihan dengan lap bersih dan alkohol. Pada poin menanggalkan APD setelah pencampuran sebesar 105 pencampuran $(95,45)$ hal ini menunjukkan bahwa penanganan APD dilakukan secara tepat sebagai upaya mengurangi risiko pencemaran dan penyebaran infeksi.

Tahap pencampuran ini didukung oleh reinforcement factor yakni dorongan untuk disiplin atas sikap yang telah dicontohkan oleh senior atau orang terdahulunya. ${ }^{11}$ APD yang sering digunakan adalah masker, baju pelindung, dan sarung tangan. Penanganan APD yang baik dapat mengurangi risiko infeksi nosokomial didukung dengan sarana penanganan APD dan tempat ganti pakaian yang baik. Kesesuaian dalam cuci tangan pencampuran $100 \%$ didukung dengan tersedianya sarana cuci tangan dan kesadaran dalam upaya pencegahan infeksi secara dini yakni dengan sabun antiseptik atau hand rub. Cuci tangan adalah salah satu upaya penghilangan debu dan kotoran minimal secara mekanis. ${ }^{12}$

Prosedur tahap penyimpanan yaitu menyimpan sediaan di tempat kedap cahaya (gelap atau bahan dari aluminium foil) dan suhu penyimpanan $2-8^{\circ} \mathrm{C}$ atau sesuai dengan syarat sediaan. Salah satu penyebab medication error adalah kesalahan dalam penyimpanan yang dapat diakibatkan oleh ketidaktahuan prosedur penyimpanan yang benar. Seharusnya dalam disribusi obat ke ruangan disertai lembar prosedur penyimpanan.

Pada tahap pembuangan terdiri atas 5 poin. Hampir seluruh poin kesesuaian mencapai $100 \%$ kecuali poin menggunakan APD sebesar 96 pencampuran $(87,27 \%)$ hal ini disebabkan faktor kepraktisan, menurut teori Health belief model bahwa SDM merasa mendapatkan ancaman yang membahayakan apabila tidak patuh menggunakan APD dalam praktek dispensing. ${ }^{11}$ Penempatan limbah sesuai dengan jenisnya, pelabelan, dan pembuangan sudah sesuai dengan Kepmenkes No. 1428/MENKES/SK/XII/2006. Kesesuaian prosedur cuci tangan sebesar $100 \%$ untuk upaya dekontaminasi minimal setelah menangani limbah.

Dari 15 angket tingkat pengetahuan yang diinterpretasikan dengan kategori teori Arikunto, 2006 bahwa sebagian besar petugas pencampuran di ICU dan NICU memiliki tingkat pengetahuan sangat baik, sehingga diharapkan tidak mengalami kendala dalam melakukan pencampuran sediaan parenteral. Nilai terendah pada soal nomor 3 yaitu keikutsertaan dalam pelatihan aseptic dispensing dan jawaban tertinggi pada soal nomor 6 tentang prosedur cuci tangan sesuai dengan SPO sebelum maupun setelah melakukan pencampuran sediaan parenteral. Diketahui bahwa SDM sudah mengetahui definisi dan pentingnya aseptic dispensing. Keikutsertaan dalam pelatihan $(53,3 \%)$ dan mencari referensi ilmu mengenai aseptic dispensing $(73,3 \%)$ penting untuk meningkatkan mutu kerja dan pelayanan khususnya dalam bidang dispensing sediaan parenteral, karena pemberian pelatihan memberikan efek pengetahuan dan peningkatan mutu kerja SDM. ${ }^{4}$ Dibutuhkan pelatihan secara berkala untuk meningkatkan pengetahuan SDM. Kendala yang sering muncul adalah karena banyaknya pasien dan keterbatasan waktu dalam pencampuran obat, SDM kurang pengetahuan tentang aseptic dispensing, dan sarana untuk melaksanakan aseptic dispensing kurang lengkap.

Faktor berikutnya yang mendukung aseptic dispensing adalah ketersediaan peralatan dan ruang. Berdasarkan hasil pengamatan bahwa peralatan di ICU dan NICU RSUD Dr. Saiful Anwar Malang belum sepenuhnya sesuai dengan Pedoman Dasar Dispensing Sediaan Steril Depkes RI Tahun 2009, yaitu tidak ada LAF-BSC dan passbox. Keterbatasan alat menyebabkan kesulitan SDM dalam melakukan pencampuran sediaan parenteral. Di NICU terdapat ruang pengoplosan obat menyerupai LAFBSC sehingga mendukung hasil kesesuaian aseptic dispensing yang cukup tinggi di NICU daripada di ICU. 


\section{Daftar Pustaka}

1. Surahman E, Mandalas E, Kardinah, Endah I. 2008. Evaluasi Penggunaan Sediaan Farmasi Intravena Untuk Penyakit Infeksi Pada Salah Satu Rumah Sakit Swasta di Kota Bandung. Bandung: Majalah Ilmu Kefarmasian, Vol V, No.1, April 2008, 21 - 39.

2. American Society of Health-System Pharmacist. 2008. ASHP Discussion Guide for Compounding Steril Preparations. http://www.ashp.org/_s_ashp/docs/files_797guide.pdf. Diakses tanggal 7 September 2014 pukul 19.00 WIB.

3. Taxis $K$ dan Baber N. Incidence and Severity of Intravenous Drug Errors in A German Hospital. Eur $J$ Clin Pharmacol 2004; 59: 815-817.

4. Maharani L., Achmad A., Utami, ED. 2013. Pengaruh Edukasi Apoteker Terhadap Sikap dan Pengetahuan Perawat Tentang Pencampuran Sediaan Parenteral. Purwokerto: Jurnal Keperawatan Soedirman ( The Soedirman Journal of Nursing), Volume 8, No.2, Juli 2013.

5. Direktorat Jendral Bina Farmasi Komunitas dan Klinik. 2009. Pedoman Dasar Dispensing Sediaan Steril. Jakarta: Depkes RI.

6. Tissot E,Cornette C, Demoly P, Jacquet M, Barele F, and Capellier G. 1999. Medication Errors at The Administration Stage In An Intensive Care Unit. Intensive Care Med 1999; 25: 353-359.

7. Giorgi I, Bertrand G, Caroline, and Pascal B. 2010. Evaluation Tools To Prevent Drug Incompatibilities In Paediatric And Neonatal Intensive Care Units. Pharm World Sci 2010 Aug 17;32(4):520-9.

8. RSSA Malang. 2013. Profil RSUD Dr. Saiful Anwar Malang Tahun 2013. Malang: RSUD Dr. Saiful Anwar Malang

9. Hendra, Yuli. 2011. Beberapa Faktor yang Berhubungan dengan Praktik Pemakaian Alat Pelindung Diri (APD) pada Radiografer di Instalasi Radiologi 4 Rumah Sakit di Kota Semarang. Jurnal Unismuh Vol 7 No.1 Tahun 2011. Semarang: Universitas Muhammadiyah Semarang.

10. Sayuti H, Hanis M, Kadir A. 2013. Analisis Pelaksanaan Kewaspadaan Universal Oleh Perawat di Rung IGD dan ICU RSU Massenrempulu Kabupaten Enrekang. Volume 3 Nomor 2 Tahun 2013 ISSN: 2302-1721. Makassar: Stikes Nani Hasanuddin Makassar.

11. Green L, Kreuter. 2000. Health Prmotion Planning An Educational and Enviromental Approach, $2^{\text {nd }}$ Edition. California: Mayfield Publishing Company.

12. Sulaiha SA, Ling WY, Chin LJ, Eow WL, Faiz M, Tan NCF. 2010. The Lack of Effective Hand Washing Practice Despite High Level of Knowledge and Awareness In Medical Students of Clinical Years. IeJSME 2010:4(2): 18-26. Malaysia: Department of Obstretrics \& Gynecology International Medical University. 